\title{
Novel strategy using live non-pathogenic Leishmania expressing selected parasite antigens as a candidate vaccine for leishmaniasis
}

\author{
Sima Rafati ${ }^{*}$, Amir Mizbani ${ }^{1}$, Tahere Taheri ${ }^{1}$, Farnaz Zahedifard ${ }^{1}$, Yasaman Taslimi ${ }^{1}$, Barbara Papadopoulou ${ }^{2}$ \\ From Institut Pasteur International Network Annual Scientific Meeting \\ Hong Kong. 22-23 November 2010
}

Parasites of the genus Leishmania are intracellular protozoa which are transmitted to their mammalian host by the bite of infected sand flies and cause a group of diseases known as Leishmaniasis. Despite attempting different vaccination strategies, no human vaccine is yet available against this disease. There is increasing evidence that presence of a small number of live parasites is necessary to maintain durable immunity, and the only way to meet this requirement is by using attenuated live vaccines [1]. The main obstacle about attenuated live strains is the risk of reversion of the organism to its virulent state. Another approach to reach this strategy is to use nonpathogenic Leishmania such as L. tarentolae. This parasite is lizard parasite and has never been found associated with any leishmaniasis in humans and is considered as non-pathogenic to humans. Previous studies have shown that $L$. tarentolae can be used as a live vaccine against $L$. donovani and elicit a protective Th1 immune response [2]. Recently, by comparative genomic analysis and expression profiles of well-characterized virulence factors such as GP63, CPB, LPG3, Amastin and A2 between pathogenic Leishmania species (e.g. L. major, L. infantum and $L$. braziliensis) and non pathogenic L. tarentolae revealed that only A2 is absent at the level of DNA [3]. A recombinant $L$. tarentolae expressing the A2 protein was generated and its potential as a live vaccine against L. infantum infection in BALB/c mice was examined [4]. The A2 expressing recombinant parasites showed higher macrophage infectivity in comparison to L. tarentolae used as a control. Immunization (i.v. and i.p.) of BALB/c

\footnotetext{
* Correspondence: sima-rafatisy@pasteur.ac.ir

'Molecular Immunology and Vaccine Research Laboratory, Pasteur Institute of Iran, Tehran, Iran

Full list of author information is available at the end of the article
}

mice with recombinant $L$. tarentolae A2 elicited a strong protective immunity against virulent $L$. infantum challenge, manifested by a dramatic decrease in parasite burdens in the liver and the spleen of immunized mice. IFN-g production upon antigen stimulation indicated that protection is associated with a Th1 cell-mediated immunity accompanied by reduced levels of IL- 5 production (the Th2 type response). Interestingly, although IFN-g production is also induced in groups of mice immunized with wild type $L$. tarentolae, cytokine levels are increased in the group immunized with the recombinant $L$. tarentolae A2 and especially when the vaccine regimen is administered via the i.p. route [4]. In continuation of these promising results, we are expanded this idea against $L$. major infection as a novel vaccine regimen by including two immunogenic parasite proteins (cysteine proteinases $\mathrm{A}$ and $\mathrm{B}, \mathrm{CPA} / \mathrm{CPB}$ ).

\section{Author details \\ ${ }^{1}$ Molecular Immunology and Vaccine Research Laboratory, Pasteur Institute of Iran, Tehran, Iran. ${ }^{2}$ Research Centre in Infectious Diseases, CHUL Research Centre and Department of Medical Biology, Faculty of Medicine, Laval University, Quebec G1V 4G2, Canada.}

Published: 10 January 2011

\section{References}

1. Okwor I, Liu D, Uzonna J: Qualitative differences in the early immune response to live and killed Leishmania major: Implications for vaccination strategies against Leishmaniasis. Vaccine 2009, 27:2554-2562.

2. Breton M, Tremblay MJ, Ouellette M, Papadopoulou B: Live nonpathogenic parasitic vector as a candidate vaccine against visceral leishmaniasis. Infect Immun 2005, 73:6372-6782.

3. Azizi H, Hassani K, Taslimi Y, Najafabadi HS, Papadopoulou B, Rafati S: Searching for virulence factors in the non-pathogenic parasite to humans Leishmania tarentolae. Parasitology 2009, 136:723-735. 
4. Mizbani A, Taheri T, Zahedifard F, Taslimi Y, Azizi H, Azadmanesh K, Papadopoulou B, Rafati S: Recombinant Leishmania tarentolae expressing the $A 2$ virulence gene as a novel candidate vaccine against visceral leishmaniasis. Vaccine 2009, 28:53-62.

doi:10.1016/j.vaccine.2009.01.133

Cite this article as: Rafati et al:: Novel strategy using live non-

pathogenic Leishmania expressing selected parasite antigens as a candidate vaccine for leishmaniasis. BMC Proceedings 2011 5(Suppl 1):06.

Submit your next manuscript to BioMed Central and take full advantage of:

- Convenient online submission

- Thorough peer review

- No space constraints or color figure charges

- Immediate publication on acceptance

- Inclusion in PubMed, CAS, Scopus and Google Scholar

- Research which is freely available for redistribution

Submit your manuscript at www.biomedcentral.com/submit

() BioMed Central 